Journal of Research in Interprofessional

Practice and

Education

Vol. 3.2

August, 2013
Journal of Research in Interprofessional Practice and Education (JRIPE)

Vol. 3.2

(c) 2013

Corresponding Author: Jeff Cain. Email: 'jeff.cain@ukky.edú,

\section{Exploring Social Media's Potential in Interprofessional Education}

\author{
Jeff Cain, EdD \& Katherine Chretien, MD
}

\begin{abstract}
Social media applications such as Facebook, Twitter, and blogs have become part of mainstream society and are currently being used throughout health professions education. The asynchronous nature and conversational aspects of social media permit learners to collaborate with and learn from others in different fields. Interprofessional education (IPE) is a growing paradigm in health professions schools for a variety of reasons, including the desire to teach future practitioners how to communicate with each other and engage in collaborative care. Due to the interdisciplinary nature of IPE curricula, those programs must overcome numerous logistical barriers to be successful. Finding suitable times and locations for interprofessional students to meet and arranging opportunities for them to collaborate on healthcare issues are just two of the logistical impediments to IPE implementation. Fortunately, the asynchronous, conversational, and collaborative aspects of social media applications enable them to facilitate interprofessional communication and alleviate some of the time and space issues. In this article, we describe in further detail the merits of social media relevant to IPE, provide specific examples of how social media can be used to enhance aspects of IPE programs, and make a call for further research in this area.
\end{abstract}

Keywords: Social media; Online learning; Social networking; Online community

\section{Introduction}

Social media use has grown at an astounding rate considering that most of the major applications (Facebook, Twitter, YouTube, WordPress, etc.) have been launched in the last 5 to 7 years. Facebook alone has an estimated 845 million active users [1]. More than 340 million people read blogs hosted by WordPress each month [2], and that is just one of several blogging applications. Over 4 billion YouTube videos are viewed each day [3], and it only took 38 months from the first tweet to reach the one billionth tweet [4].

The use of social media now crosses all facets of personal and professional lives. Many medical educators recognize that social media, web tools and applications that facilitate online interaction and information sharing, has the potential to transform learning environments and engage "digital-native" learners. Blogs, for example, have served as a vehicle for reflective writing within the medicine clerkship, as well as a vehicle to deliver clinical pearls for trainees, by trainees $[5,6]$. On Twitter, a character-limited microblogging site, a medical school faculty member hosts a weekly medical education "chat" centred around the chosen medical education topic of the week, in which anyone with an interest can drop in on the online conversation and participate. Virtual Twitter journal clubs also connect people from diverse geographic locations and specialties to discuss articles. One journal club addressing an article on surgical checklists welcomed lead manuscript author Atul Gawande to the discussion. Lectures delivered by podcast allow learners to personalize their exposure to content based on their own learning style preferences. Facebook has 
2

Social Media for Interprofessional Education

Cain \& Chretien

Journal of Research in Interprofessional Practice and Education

Vol. 3.2

August, 2013 been successfully used as an informal learning environment to extend course content for pharmacy students and expose them to external guests [7]. These examples are just a small sample of teaching and learning strategies utilizing social media in academic health professions schools.

\section{Educational need for interprofessional education}

Interprofessional education (IPE) is one contemporary educational paradigm increasing in importance that could potentially benefit from strategies utilizing social media. "Interprofessional education occurs when two or more professions learn about, from and with each other to enable effective collaboration and improve health outcomes" $[8$, n.p. $]$.

There are numerous drivers of IPE, including the desire to improve patient outcomes through collaborative interprofessional efforts [9]. When healthcare personnel work in tandem, the patient benefits from higher quality of care. IPE has also been shown to be effective in reducing negative stereotypes of the professions, which is necessary for positive working relationships [10].

The increased focus on interprofessional education prompted an expert panel representing six different health professions education associations to draft core competencies of interprofessional collaborative practice. These competencies were developed to meet the need for co-ordinated interprofessional efforts, to enhance curricular development, and to assist integration of interprofessional education content consistent with respective accrediting bodies. Accrediting agencies for health professions education have also begun to include competencies that address collaboration among the professions [11].

\section{Challenges of interprofessional education}

Several challenges face health professions educators who wish to successfully implement an IPE program. Logistics may be the primary impediment to training different health professions students together in the same environment. Many universities, colleges, and schools do not offer programs for all the health professions, thereby limiting the scope of interprofessional experiences. Even those programs fortunate enough to reside in large academic medical centers may find that existing course and program requirements inhibit the ability to schedule students simultaneously into IPE classes and settings [12]. Many health professions programs operate on different academic calendars, and because of the sheer numbers of courses required across the programs, it may seem virtually impossible to find a day, time, and location that is convenient/available to all students [13]. Furthermore, organizing interprofessional students into groups that do not over or under represent any single profession can be challenging. Beyond those logistical issues, developing appropriate instructional scenarios has been cited as a potential barrier [14]. The time and resources needed to implement effective IPE activities is significant, and faculty who are skilled and willing to facilitate these activities must be supported [13]. Gaining buy-in from administrators, faculty, and students that IPE is worth the effort may also be difficult [15]. In addition to the aforementioned issues, one 
3

Social Media for Interprofessional Education

Cain \& Chretien

Journal of Research in Interprofessional Practice and Education

Vol. 3.2

August, 2013 study revealed that "turf battles" are another potential problem when implementing IPE activities [16]. If there is no centralized IPE organizational unit directing the activities, academic administrators from the different programs may vie for control of resources and programming, thereby creating a less than ideal atmosphere for collaboration.

\section{Social media's promise for interprofessional education}

The near ubiquity and ease of use of social media applications like Facebook, Twitter, and blogs enhance the possibilities of communication between and among users of diverse backgrounds. Many of these attributes make social media a potential solution to some of the logistical issues impeding IPE. While technology-facilitated communication differs from traditional face-to-face interactions, it provides users with opportunities to develop relationships and gain perspectives that otherwise would not have been possible. The ability to network with others through social media is magnified when time and physical space restraints are removed. These online spaces may also remove some of the barriers to interaction among users that are more reserved in face-to-face settings [17]. Safe learning environments that allow students to reflect upon and grapple with interprofessional healthcare issues are important for developing understanding and appreciation for the different perspectives [18].

Communication among members of different healthcare professions is an important element of IPE. This includes sharing information pertaining to roles/contributions and learning how to work together to achieve optimal patient outcomes [15]. Building community is an important aspect of interprofessional education and the networking aspects of these media provide a platform from which communities of practice among the participants can be developed [19]. Given their asynchronous nature, social media applications may represent an ideal way to overcome the logistical scheduling issues that plague IPE, potentially facilitating some of the communicative aspects. Nurturing of collegial relationships can occur in the online settings when time/space constraints otherwise prevent personal interactions. If properly designed, this might allow the limited face-to-face interactions to concentrate on higher order learning activities rather than on relationship building.

One of the more obvious attributes of social media that make it conducive to interprofessional activities is its inherent nature as an informal environment. The impact of informal learning (occurring outside formal classroom settings) should not be underestimated in shaping socialization processes among different professions [18].

The use of social media for education is supported by learning theory, particularly as it applies to the Millennial or Net generation. The Millennial generation, born after 1980, is generally described as being highly technology dependent, and they far outpace older Americans in their adoption and use of social media. Technology use is cited by Millennial individuals as the defining characteristic of their generational cohort, and more than $75 \%$ of them report using social media. Conversing via social media is an ordinary mode of communication for that generation [20]. 
4

Social Media for Interprofessional Education

Cain \& Chretien

Journal of Research in Interprofessional Practice and Education

Vol. 3.2

August, 2013
Newer theories/paradigms of learning, such as connectivism, highlight the learning mechanisms that can occur through online social platforms by Millennial learners who have matured in digital environments [21]. Selwyn states that social media may be changing the nature of learners' relationships with information and knowledge [22]. The shared community and group conversation spaces provided through social media excite students and theoretically should contribute to their motivation to learn [23]. Connectivism posits that the informal information exchange through social networks supported with digital tools is a primary component of the learning process. Learning becomes a lifelong system of networked activities. Although some of these networked conversations will be weak pieces of information, when surrounded by valid and strong knowledge components, the weaker conversations become a connected stable component of the overall knowledge base [24]. Not unlike constructivist learning theory, connectivism presumes that knowledge is formed through an individual's interactions with the world around him/her. This world can be physical in nature or the increasingly more common digital world.

In one survey of technology experts and stakeholders, participants predicted that younger generations growing up in hyperconnected mobile web environments will become nimble multitaskers with the ability to coalesce fragmented online conversations into meaningful information [25]. These networks of users create "community" knowledge through co-operation and conversations, and learning occurs by connecting these information sources. The ability to nurture and maintain these connections is necessary to facilitate continuous learning [26].

Using a framework of connectivism, some examples of how social media could potentially be used as part of an IPE program include

Facebook group page(s) populated by student and faculty members across different professional programs. The group page could be used as an informal environment with specific activities such as posting and responding to interprofessional practice issues. Posting could be in response to hypothetical healthcare cases, or students could share aspects of their respective professions with each other within the shared online group space. One activity could be posting "facts and myths" about their own profession or even what their perceptions are of the other professions. From a connectivism standpoint, the conversation and communication elements are what matter the most, as they contribute to community knowledge building.

Wiki(s) containing a variety of patient safety or quality improvement topics in which members of the interprofessional teams post their unique contributions and/or questions based upon the perspectives of their individual fields. Team-based wiki development could promote appreciation of knowledge and input from others.

Group (multi-author) blog(s) used for students to reflect upon their interprofessional experiences. The posts could be specific assign- 
5

Social Media for Interprofessional Education

Cain \& Chretien

Journal of Research in Interprofessional Practice and Education

Vol. 3.2

August, 2013 ments or they could consist simply of thoughts or ideas that occur to students as they engage in interprofessional activities.

These are just a few examples that highlight potential social media strategies that could be implemented into IPE programs. As in the Wiki example above, social media strategies could be used to address shared competencies such as professionalism or patient safety. The community of users creating the Wiki contribute to the knowledge base. Of course, social media should only be used when the instructional strategy warrants and not implemented for its own sake.

\section{Barriers to social media use in interprofessional education}

For such innovations of social media use for IPE to succeed, potential barriers must be anticipated and addressed. Buy-in from department chairs and administration from early stages of curricular development is crucial. In social media applications involving discussions around patient cases or patient safety/quality improvement, a consultation with a representative of an institution's legal department can be valuable. Access to particular platforms can be an issue, due to institutional firewalls; IT departments may be able to grant specific permissions with administration buy-in. In other cases, this can be a non-starter for using a particular blocked tool. Specific guidelines for trainee online posting, paying attention to HIPAA privacy concerns when relevant, adhering to professionalism standards, and a method for monitoring and moderating online discussions may also reduce institutional resistance due to professionalism concerns. Finally, time and technical proficiency can be barriers for both faculty moderators and trainees. Appropriate faculty development and time budgeted for both learners and faculty to become proficient with a particular technology is critical in order to achieve learning goals.

One important point we want to make clear is that social media should constitute only a portion of an IPE program. Clearly, students working together in faceto-face situations with actual healthcare problems to solve provide a more realistic introduction to collaborative practice than would social media conversations.

\section{Future research}

We have provided several potential scenarios in which social media use can aid in interprofessional education efforts. Research on these educational methods is sparse $[27,28]$, however, and serious inquiry needs to be devoted to these practices and their underlying philosophies. For example, building communities of practice through a social media strategy is one avenue in which research could be framed around a connectivist learning paradigm. Communities of practice involve groups of practitioners who interact with each other to frame issues, brainstorm, validate and share information, and make decisions, all of which contribute to learning in practice [29]. Computer-based information technologies are often considered integral to fostering these communities, and the information-sharing aspects of social media make those applications particularly suitable. Research should be specific to the application. Numerous social media applications currently exist, each with their 
6

Social Media for Interprofessional Education

Cain \& Chretien

Journal of Research in Interprofessional Practice and Education

Vol. 3.2

August, 2013 own unique strengths, weaknesses, adoption levels, and communication patterns that may or may not be suitable for a particular educational strategy. Experimental research confirming that use of a social media strategy strengthens relationships and builds knowledge bases across participants from diverse backgrounds and professional fields is needed. Can students learn not only about, but also to trust the skills, expertise, knowledge, and contributions that others bring to the healthcare environment? Just how valuable are informal learning environments to the overall development of future interprofessional practitioners? Are today's digital learners truly capable of building connected relationships online that carry forward to traditional face-to-face environments? These are just a few of the unanswered questions that we hope other researchers will begin to examine. The suggested research is not without challenges, including the current lack of IPE activities conducted via social media. A second but potentially more difficult task is developing valid instruments to measure some of the aforementioned abstract constructs.

\section{Conclusion}

Social media can help medical educators overcome some of the challenges that IPE has traditionally faced. It could serve as an effective tool to help interprofessional students learn about each other's different roles and perspectives, thereby building trust. More importantly, social media can also help students learn with each other in a shared online space, working as a team to provide solutions to problems in which every member's contribution is both valued and respected. Indeed, used as an adjunct, social media can help build the foundation for lifelong interprofessional learning-an unmet need in our current healthcare environment.

\section{References}

1. Facebook_Newsroom. (n.d.). Key Facts. URL: ihttp://newsroom.fb.com/content/default.aspxí ?? News AreaId $=22 ![$ April 12, 2012].

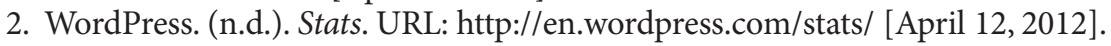

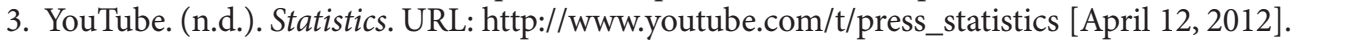

4. KISSmetrics. (n.d.). Twitter statistics 2012. URL: 'httpp://blog.kissmetrics.com/twitter-_statisticss/i [March 15, 2012].

5. Chretien, K., Goldman, E., \& Faselis, C. (2008). The reflective writing class blog: Using technology to promote reflection and professional development. Journal of General Internal Medicine, 23(12), 2066-2070.

6. Renal Fellow Network. (n.d.). URL:'http:///renalfellow.blogspot.com! [April 11, 2012].

7. Cain, J., \& Policastri, A. (2012). Using Facebook as an informal learning environment. American Journal of Pharmaceutical Education, 75(10), Article 207.

8. World Health Organization_(2010)_Eramework for action_on interprofessional education \& sol-

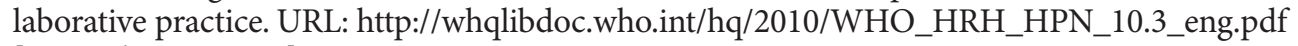
[December 19, 2011].

9. Hammick, M., Freeth, D., Koppel, I., Reeves, S., \& Barr, H. (2007). A best evidence systematic review of interprofessional education: BEME Guide no. 9. Medical Teacher, 29(8), 735-751.

10. Carpenter, J. (1995). Doctors and nurses: Stereotypes and stereotype change in interprofessional education. Journal of Interprofessional Care, 9(2), 151-161.

11. Interprofessional Education Collaborative Expert Panel. (2011). Core competencies for interprofessional collaborative practice: Report of an expert panel. Washington D.C.: Interprofessional Education Collaborative.

12. Finch, J. (2000). Interprofessional education and teamworking: A view from the education providers. British Medical Journal, 321(7269), 1138-1140. 
JRIPE

7

Social Media for Interprofessional Education

Cain \& Chretien

Journal of Research in Interprofessional Practice and Education

Vol. 3.2

August, 2013

\section{Journal of Research in Interprofessional Practice and Education}

13. Gilbert, J.H.V. (2005). Interprofessional learning and higher education structural barriers. Journal of Interprofessional Care, 19(S1), 87-106.

14. Barrett, G., Greenwood, R., \& Ross, K. (2003). Integrating interprofessional education into 10 health and social care programmes. Journal of Interprofessional Care, 17(3), 293-301.

15. Buring, S.M., Bhushan, A., Broeseker, A., Conway, S., Duncan-Hewitt, W., Hansen, L., \& Westburg, S. (2009). Interprofessional education: Definitions, student competencies, and guidelines for implementation. American Journal of Pharmaceutical Education, 73(4), Article 4.

16. Curran, V., Deacon, D., \& Fleet, L. (2005). Academic administrators attitudes towards Interprofessional education in Canadian schools of health professional education. Journal of Interprofessional Care, 1, 76-86.

17. Dubrovsky, V., Kiesler, S., \& Sethna, B.N. (1991). The equalization phenomenon: Status effects in computer-mediated and face-to-face decision-making groups. Human-Computer Interaction, $6,119-146$.

18. Oandasan, I., \& Reeves, S.C. (2005). Key elements for interprofessional education. Part 1: The learner, the educator and the learning context. Journal of Interprofessional Care, 19(S1), 21-38.

19. Sterrett, S.E. (2010). Becoming an interprofessional community of practice: A qualitative study of an interprofessional fellowship. Journal of Research in Interprofessional Practice and Education, 1(3), 247-264.

20. Pew Research_Center (2010).Millennials: A portrait of generation next.URL: torg/files/2010/10/millennials-confident-connected-open-to-change.pdf́l['[September 7, 2012].

21. Siemens, G. (2005). Connectivism: A learning theory for the digital age. International Journal of Instructional Technology and Distance Learning, 2(1), 3-10.

22. Selwyn_N_(2012)_Social media_in_bigher_education. The_Europa_Korld of Learning 2012. URL:

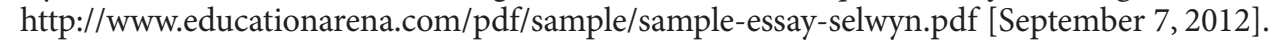

23. Mason, R., \& Rennie, F. (2007). Using Web 2.0 for learning in the community. The Internet and Higher Education, 10(3), 196-203.

24. Bessenyei, I. (2008). Learning and teaching in the information society. Elearning 2.0 and connectivism. Journal of Social Informatics, 5(9), 4-14.

25. Anderson, J.Q., \& Rainie, L. (2012). Millennials_will benefit and suffer due_to their hyperson= ,nected_lives. Pew_Research Center. URL:ibttp://pewinternet.org/_/medial/_Files/Reports_/2012i '/PIP_Future_of_Internet_2012_Young_brains_PDE.pdffi_[September 7, 2012].

26. Bell, F. (2011). Connectivism: Its place in theory-informed research and innovation in technology-enabled learning. The International Review of Research in Open and Distance Learning, 12(3), 98-118.

27. Chen, B., \& Bryer, T. (2012). Investigating instructional strategies for using social media in formal and informal learning. Intern Rev Res Open Distance Learn, 13(1), 87-104.

28. Hew, K.F. (2011). Students' and teachers' use of Facebook. Computers in Human Behavior, 27(2), 662-676.

29. Parboosingh, J.T. (2002). Physician communities of practice: Where learning and practice are inseparable. Journal of Continuing Education in the Health Professions, 22(4), 230-236. 